\title{
From the Balanced Measure of Psychological Needs (BMPN) to Employee Engagement: Indicators that Matter
}

\author{
Franklin M. Lartey ${ }^{1}, \&$ Phillip M. Randall ${ }^{2}$ \\ ${ }^{1}$ Cox Communications, Atlanta, GA, USA \\ ${ }^{2}$ School of Business and Technology, Capella University, Minneapolis, USA \\ Correspondence: Franklin M. Lartey, Cox Communications, 6305 Peachtree Dunwoody Road, Atlanta, GA 30328, \\ USA.
}

Received: May 4, 2021

doi:10.5539/ibr.v14n6p99
Accepted: May 20, 2021

Online Published: May 25, 2021

URL: https://doi.org/10.5539/ibr.v14n6p99

\begin{abstract}
The purpose of this study was to investigate if confidence, interest, authenticity, and loneliness as independent variables, could help predict employee engagement, the dependent variable. In this setting, the independent variables were indicators of the Balanced Measure of Psychological Needs (BMPN) and the dependent variable was obtained using the Utrecht Work Engagement Scale (UWES-9). After surveying 151 participants in the United States, 17 responses were removed from the final dataset during data and assumptions validation. A multiple regression model was created using the remaining 134 valid cases. Our findings confirmed the existence of a statistically significant relationship between confidence, interest, and authenticity in predicting employee engagement. Only, we could not establish a statistically significant relationship between loneliness and engagement, in contrast to some prior research studies. These findings have significant implications for practitioners and researchers as documented in this article. For example, the findings can be useful for employees in determining their future career path, as they need to first look at what interests them. Indeed, interest was identified as the greatest determinant of engagement as compared to the other three predictors. These findings also suggest that managers can keep their employees engaged by assigning them functions or tasks that are aligned with their interests.
\end{abstract}

Keywords: confidence, interest, authenticity, loneliness, engagement, employee engagement, psychological needs, BMPN, UWES

\section{Introduction}

The relationship between employee engagement and their psychological needs is an ongoing subject for scientific inquiry. According to Robertson and Cooper (2010), the focus of employee engagement has been overly concentrated on employee commitment, attachment, and citizenship rather than employee 'full engagement' which includes employee well-being and an improved basis for constructing lasting benefits for the employee and the organization. Generally, most employee engagement surveys involve aspects of engagement that are related to employee behavior, such as organizational citizenship and/or organizational commitment and attachment, or factors such as knowing what to expect (Meyer, 1997; Organ \& Paine, 1999; Harter et al., 2002).

This study suggests that full engagement may well be extended to include such components as confidence, interest, authenticity, and loneliness which are elements of the Balanced Measure of Psychological Needs (BMPN) scale. In defining employee engagement and the associated full engagement, employee engagement has been reported as a critical and essential contributor to organizational productivity, employee retention, customer satisfaction, as well as organizational effectiveness (Shuck, Rocco, \& Albornoz, 2011; Kim, Kolb, \& Kim, 2013; Kuntz \& Roberts, 2014).

\section{Literature Review}

\subsection{Balanced Measure of Psychological Needs (BMPN)}

The term "basic psychological need" is defined by Ryan (1995) as an intellectual ingredient that is indispensable for a person's adaptation, integrity, and growth. As such, a need or desire is considered "basic psychological need" only when its fulfillment is indispensable to people's well-being and its absence may increase the negative manifestations of passivity, ill-being, and defensiveness (Ryan \& Deci, 2000a; Vansteenkiste \& Ryan, 2013). 
Ryan and Deci (2002) stated that three basic psychological needs existed within self-determination theory: autonomy, competence, and relatedness. These three psychological needs are fundamentals to employee engagement and play a prominent role in development, adjustment, and wellness across cultures (Ryan \& Deci 2017). Moreover, they are synergistic with components of Self-Efficacy Theory as set forth and defined in this study.

Reportedly, the most widely used need-satisfaction measure, the Basic Psychological Needs Scale (BPNS) has been found to be questionable (Johnston \& Finney, 2010). However, Sheldon and Hilpert (2012) advanced the proposition that their BMPN model comparisons is an alternative and may well be an improved instrument to be used by Self-Determination Theory researchers. Thus, the BMPN was employed in this study to investigate the relationship between employee engagement and their psychological needs utilizing the strengths of the BMPN instrument to study relevant constructs and variable relationships.

The strength of the psychological need assessment instruments is that they are effective in measuring those constructs and/or variables that are pertinent to employee engagement. The affiliation of interest and autonomy, loneliness and relatedness are clearly present and relevant for this study. The narrative discussion that embodies the relevancy of the self-determination theory and the self-efficacy theory possesses and explains the connectivity between the two theories and offers technical support for their resonance and both their study purpose and kinship.

\subsection{Employee Engagement}

As an early provider of a definition of employee engagement, Kahn (1990) defined engagement as "the harnessing of organizational members' selves to their work roles; in engagement, people employ and express themselves physically, cognitively, and emotionally during role performances" (p. 694).

Although employee engagement has both enjoyed and endured several definitions over the years (Tate, Lartey, \& Randall, 2021), it is defined by Shuck and Wollard (2010) as "an individual employee's cognitive, emotional, and behavioral state directed toward desired organizational outcomes" (p. 103). According to Kim, Kolb, and Kim (2013), "engagement might be viewed as a proactive and fundamental approach to organizational performance and sustainability" (p. 249). Consequently, employees might be expected to be more effective workers resulting in improved organizational productivity and sustainability.

For the purposes of this research, we offer a practitioner's definition based on the assumption advanced by Ababneh and Macky (2015) that engagement is something that can be changed, and that which is changed is done so by modifying the conditions under which one's work is offered. This definition is aligned with that of Lartey (2021) suggesting that engagement is:

a two-way relationship between an organization and a worker, in which the organization provides the worker with the environment and conditions to be successful through good leadership and management, and the worker provides the organization with a positive and self-motivated performance leading to the achievement of the organizational mission, vision, purpose, and goals (p. 137).

This definition of engagement suggests the requirement for the employee to use intrinsic forces, which can be explained by the self-efficacy theory.

\subsection{Self-Efficacy Theory}

To define and paraphrase Bandura's own words, self-efficacy is one's belief in their ability to influence events that effect one's life and to have control over the way these events are experienced. (Bandura, 1994). The self-efficacy theory maintains that people are likely to engage in activities to the extent that they perceive themselves to be capable and/or competent (Bandura, 1994). The term self-efficacy is used loosely and widely in education, training, and development literature, usually with a comment about the low self-efficacy of workers, learners, students, patients, citizens, etc.

People's beliefs about their efficacy can be developed by four main sources of influence. They are: 1) Performance Accomplishments achieved through various experiences. Successful experiences build a strong belief in a person's potential and efficacy; 2) Vicarious Experience provided by social models. Seeing people like oneself succeed by sustained effort raises observers' beliefs that they too possess the capabilities to master comparable activities and succeed; 3) Social Persuasion, "persuaded verbally that they possess the capabilities to master given activities are likely to mobilize greater effort and sustain it than if they harbor self-doubts and dwell on personal deficiencies when problems arise", and 4) Physiological and Emotional States, "to reduce people's stress reactions and alter their negative emotional proclivities and misinterpretations of their physical states." (Bandura, 1994, pg. 3-4). Self-efficacy is a direct predictor of the intention of one's behavior and/or one's confidence. 


\section{Research Design}

\subsection{Research Question, Hypotheses, and Conceptual Framework}

The goal of this study was to identify the indicators of the Balanced Measure of Psychological Needs (BMPN) scale that predict engagement. To that effect, the research question RQ1 was used in guiding this study:

RQ1: To what extent do Confidence, Interest, Authenticity, and Loneliness as measured by their respective indicators in the BMPN scale contribute to employee engagement as measured by the Utrecht Work Engagement Scale (UWES-9)?

A null hypothesis (H0) and an alternate hypothesis (HA) were formulated to answer the research question.

H0: There is no statistically significant relationship between Confidence, Interest, Authenticity, and Loneliness as predictors, and Employee Engagement as the outcome.

HA: There is a statistically significant relationship between Confidence, Interest, Authenticity, and Loneliness as predictors, and Employee Engagement as the outcome.

For a better representation of the research question, a conceptual model of the study was created and represented on Figure 1. This shows the four predictors or independent variables (Confidence, Interest, Authenticity, and Loneliness) used in determining the outcome or dependent variable on the right, representing Employee Engagement.

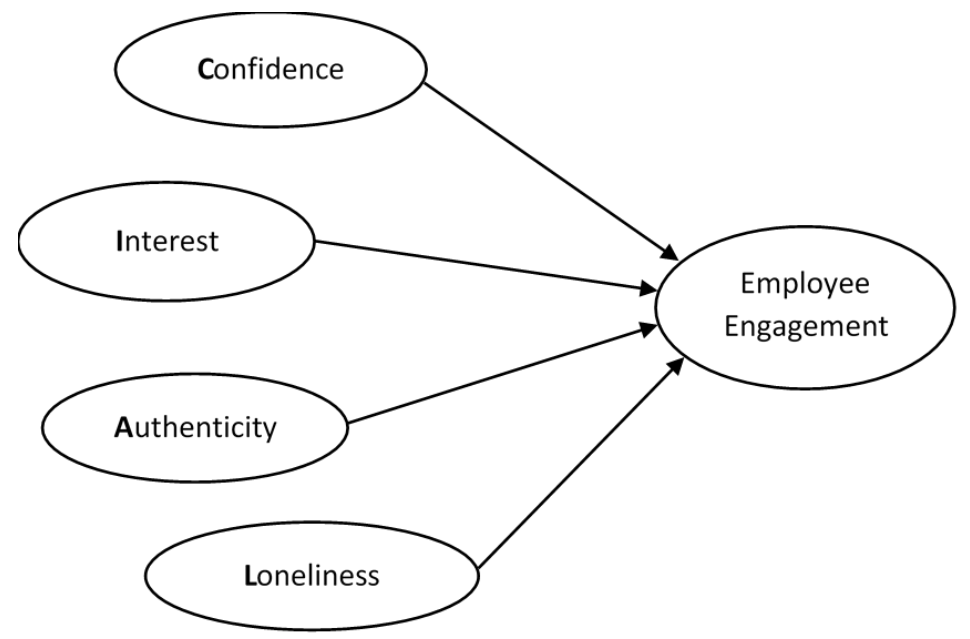

Figure 1. Conceptual model of the study suggesting that Confidence, Interest, Authenticity, and Loneliness might contribute to employee engagement

\subsection{Research Approach and Measurement Instruments}

This quantitative research study was conducted using a non-experimental correlational research approach. The study used a self-reported questionnaire administered online through a survey firm. To measure employee engagement, the questionnaire included the Utrecht Work Engagement Scale (UWES-9), a 9-item validated instrument created by Shaufeli, Bakker, and Salanova (2006). The questionnaire also included the BMPN scale, an 18-item instrument created by Sheldon and Hilpert (2012). Four of the 18 indicators were selected for this study, namely Confidence, Interest, Authenticity, and Loneliness. These indicators were identified from their related assertions as follows:

CONFIDENCE: I successfully complete difficult tasks and projects.

INTEREST: I am really doing what interests me.

AUTHENTICITY: My choices express my "true self".

LONELINESS: I feel lonely.

The reliability of the measurement instrument was calculated using the Cronbach alpha reliability statistic. The resulting Cronbach alpha showed a reliability value of .89, well above the suggested minimum of 7 (Lartey, 2021), thus confirming a high internal consistency of the survey questionnaire. As such, this study could be conducted as is, without any need for data reduction. First, the sample size needed to be analyzed. 


\subsection{Population and Sample Size}

Participants in this study were randomly selected by the online survey firm QuestionPro. Data were collected from 151 respondents, all workers in organizations within the United States (U.S.). As shown on Table 1, 71 of the participants were male representing 47 percent of the sample, and 80 were females representing 53 percent of the sample. Table 1 also shows the participants by age group, with the group of people between 23 and 39 having the highest number of participants, followed by the age group from 40 to 55 . The adequacy of the sample was confirmed through a post hoc power analysis using GPower 3.1.9.4, a statistical power analysis tool promoted by Faul, Erdfelder, Lang, and Buchner (2007). To that effect, the GPower suggested that a model with four predictors, a medium effect size $\left(f^{2}=0.15\right)$, and an error probability $(\alpha)$ of .05 , resulted in a total achieved power of .99, well above the minimum power of .80 suggested by Field (2013) and Tabachnick and Fidell (2013). This sample size also aligned with previous studies in the field of engagement. For instance, Saks (2006) used a sample of 107 participants in a study of drivers of employee engagement while Lartey and Randall (2021) used a sample of 133 cases in their analysis of the relationship between indicators of computer-mediated communication and employee engagement.

Table 1. Breakdown of the participants by gender and age group

\begin{tabular}{|c|c|c|c|c|c|c|c|c|}
\hline & & & & & Age Groups & & & \\
\hline & & & $\leq 22$ & $23-39$ & $40-55$ & $56-74$ & $75+$ & Total \\
\hline Gender & Male & Count of males & 3 & 31 & 32 & 4 & 1 & $\overline{71}$ \\
\hline & & $\%$ within males & $4.2 \%$ & $43.7 \%$ & $45.1 \%$ & $5.6 \%$ & $1.4 \%$ & $100.0 \%$ \\
\hline & & $\%$ of Total & $2.0 \%$ & $20.5 \%$ & $21.2 \%$ & $2.6 \%$ & $0.7 \%$ & $47.0 \%$ \\
\hline & Female & Count of females & 5 & 35 & 25 & 12 & 3 & 80 \\
\hline & & $\%$ within females & $6.3 \%$ & $43.8 \%$ & $31.3 \%$ & $15.0 \%$ & $3.8 \%$ & $100.0 \%$ \\
\hline & & $\%$ of Total & $3.3 \%$ & $23.2 \%$ & $16.6 \%$ & $7.9 \%$ & $2.0 \%$ & $53.0 \%$ \\
\hline Total & & Total participants & 8 & 66 & 57 & 16 & 4 & 151 \\
\hline & & $\%$ of Total & $5.3 \%$ & $43.7 \%$ & $37.7 \%$ & $10.6 \%$ & $2.6 \%$ & $100.0 \%$ \\
\hline
\end{tabular}

\section{Data Analysis}

The research question was answered through the implementation of a multiple regression model applied to the collected sample. The model would help answer the research question seeking the extent to which confidence, interest, authenticity, and loneliness contributed to employee engagement. In this setting, there was one dependent variable (engagement) and four independent variables (confidence, interest, authenticity, and loneliness). As such, a multiple regression was deemed adequate as all the variables were of scale measurement level. Prior to creating the multiple regression model, various assumptions of multiple regression needed to be analyzed as suggested by Tabachnick and Fidell (2013) and implemented by Tate, Lartey, and Randall (2019) in their study analyzing the relationship between computer mediated communication and employee engagement using multiple regression statistics.

The number of 151 cases obtained from the survey was well above the recommended minimum of 107 suggested by Tabachnick and Fidell (2013) for a multiple regression analysis. This was also confirmed by the power analysis presented earlier, showing an achieved power of .99 . Nonetheless, further descriptive analysis with a listwise exclusion of cases identified eight cases with missing values. These eight cases were removed from the sample, bringing its size to 143 cases, still well above the recommended minimum of 107 .

In addition, a subsequent descriptive statistic of the z-score showed two engagement scores and two confidence values outside the -3.29 to 3.29 range. The four cases were eliminated, bringing the sample size to 139 , still above the recommended minimum. Further descriptive analysis of the sample with 139 cases showed no univariate outlier. Multivariate outliers were analyzed using the Mahalanobis distance. After two iterations of the calculation of the Mahalobis distance, five cases identified as multivariate outliers were removed from the sample, bringing the total sample size to 134 cases.

An analysis of the skewness and kurtosis showed that all values of skewness and kurtosis were in the range from -1 to 1 , suggesting that the variables were normally distributed. Further analysis of the Shapiro Wilk and Kolmogorov-Smirnov tests confirmed the normal distribution of ENGAGEMENT, the dependent variable. Using a scatter plot with the standardized residuals on the y-axis and standardized predicted values on the $\mathrm{x}$-axis, we confirmed the homoscedasticity, normality, linearity, and independence of residuals. The variance inflection factor (VIF) confirmed the absence of multicollinearity or singularity as all the VIF values were below 10. 
A subsequent analysis of the data was conducted to ascertain the validity of the assumptions on the final dataset of 134 cases. This final sample was still above the minimum recommendation of 107 cases. A new post-hoc analysis using GPower confirmed that the achieved power stayed at .99. No univariate outlier was detected, and all other assumptions were confirmed. With that, a multiple regression model was created.

\section{Results}

After validating the assumptions of multiple regression, 17 cases were removed from the initial sample of 151 cases as follows: eight were missing values, four univariate outliers, and five multivariate outliers. The suppression of these cases brought the total sample size to 134 cases, still confirmed to be adequate for a multiple regression analysis. All the assumptions of multiple regression were validated against the final sample was deemed good for the creation of a multiple regression statistical model.

Using the command Analyze/Regression/Linear on IBM SPSS version 24, a standard multiple regression model was created to answer the research question asking if the independent variables (CONFIDENCE, INTEREST, AUTHENTICITY, and LONELINESS) contributed to the dependent variable (ENGAGEMENT). In other words, the goal was to seek if ENGAGEMENT could be predicted using the proposed independent variables or predictors.

The resulting model confirmed the existence of a significant regression equation $F(4,134)=42.8, p<.001$ as shown on Table 2 detailing the results of the analysis of variance (ANOVA). Because ANOVA tests if the $\mathrm{R}$-Square of a model is significantly greater than 0 , the null hypothesis suggesting that the R-Square of the model was equal to zero was rejected and the alternate retained. As such, it could be inferred that there was a statistically significant relationship between the DV ENGAGEMENT and the IVs CONFIDENCE, INTEREST, AUTHENTICITY, and LONELINESS.

Table 2. Analysis of variance (ANOVA) confirming a significant regression equation.

\begin{tabular}{llccccc}
\hline Model & & Sum of Squares & df & Mean Square & F & Sig. \\
\hline $1^{\mathrm{a}}$ & Regression & 2905.884 & 4 & 726.471 & 42.809 & $.000^{\mathrm{b}}$ \\
& Residual & 2189.131 & 129 & 16.970 & & \\
& Total & 5095.015 & 133 & & & \\
a. Dependent Variable: ENGAGEMENT & & & \\
b. Predictors: (Constant), LONELINESS, INTEREST, CONFIDENCE, AUTHENTICITY & & \\
\hline
\end{tabular}

The regression model summary presented on Table 3 shows an $R$-Square of .57 . This means the model can explain 57 percent of the variability in engagement as measured by the UWES-9 instrument. In other words, the predictors (CONFIDENCE, INTEREST, AUTHENTICITY, and LONELINESS) account for 57 percent of the variation in the outcome (ENGAGEMENT). The adjusted $R$-Square of the model is .557 as shown on Table 3. It provides an idea on how well the model would generalize. The difference between the $R$-Square and the adjusted $R$-Square is .013 or $1.3 \%$, computed as .570 - .557 . This shrinkage from the $R$-Square to the Adjusted $R$-Square means that if the model were derived from the population rather than a sample, it would account for approximately $1.3 \%$ less variance in the outcome, which is negligeable as difference. Based on this, we can conclude that the model is generalizable to the population.

Table 3. Model Summary

\begin{tabular}{lllll}
\hline Model & $\mathrm{R}$ & $\mathrm{R}$ Square & Adjusted R Square & Std. Error of the Estimate \\
\hline $1^{\mathrm{a}}$ & $.755^{\mathrm{a}}$ & .570 & .557 & 4.11947 \\
\hline a. Predictors: (Constant), LONELINESS, INTEREST, CONFIDENCE, AUTHENTICITY
\end{tabular}

The model created is presented on Table 4 with its coefficients showing the independent variables that contribute to the determination of engagement. Besides LONELINESS, all independent variables were statistically significant in their contribution to the dependent variable $(p<.05)$. The standardized coefficients Beta showed that the most significant predictor of ENGAGEMENT was INTEREST, followed by AUTHENTICITY, then CONFIDENCE, which were all significant $(p<.05)$. Only, LONELINESS was not significant in the determination of ENGAGEMENT $(p>.05)$. In other words, the LONELINESS predictor did not substantially contribute to the determination of ENGAGEMENT in this model. 
Table 4. Multiple regression model with coefficients

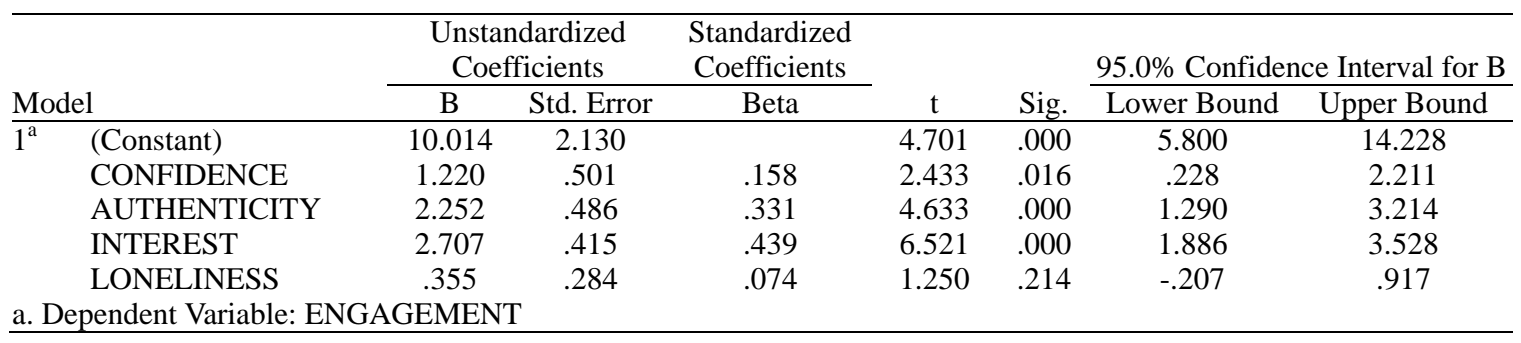

The fact that LONELINESS did not significantly contribute to ENGAGEMENT called for the creation of a model without LONELINESS to ascertain the finding and identify the resulting end model. Table 5 shows the final model summary. This model shows an R-Square of 56.5 percent with an adjusted R-Square of 55.5 percent. The difference between them was reduced to $1 \%$ compared to the previous model, confirming the generalizability of the model to the population.

Table 5. Final Model Summary

\begin{tabular}{lcccc}
\hline Model & $\mathrm{R}$ & $\mathrm{R}$ Square & Adjusted R Square & Std. Error of the Estimate \\
\hline $2^{\mathrm{a}}$ & $.752^{\mathrm{a}}$ & .565 & .555 & 4.12838 \\
\hline a Predictors: (Constant) INTEREST & CONFIDENCE & AUTHENTICITY
\end{tabular}

a. Predictors: (Constant), INTEREST, CONFIDENCE, AUTHENTICITY

Table 6 shows the final model obtained from the three predictors (CONFIDENCE, INTEREST, and AUTHENTICITY). It still shows that all three predictors are significant in predicting ENGAGEMENT and confirms the importance of INTEREST as the best contributor to ENGAGEMENT compared to the other predictors.

Table 6. Final Multiple Regression Model with Coefficients

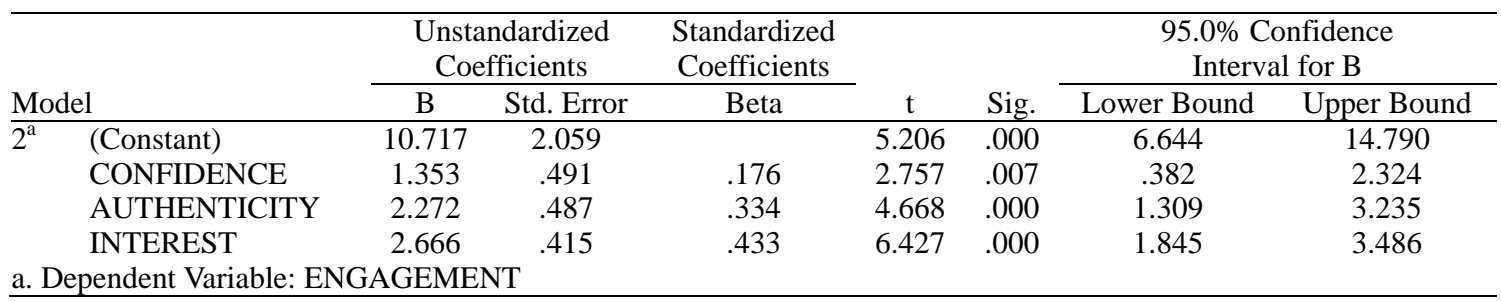

\section{Discussions, Implications, Limitations and Future Prospects}

This non-experimental correlation study was anchored around the self-efficacy theory which stipulates that people are willing to engage in activities when they perceive that they are capable and competent to complete them. The study analyzed the relationship between the independent variables or predictors (CONFIDENCE, INTEREST, AUTHENTICITY, and LONELINESS) and the outcome or dependent variable (ENGAGEMENT). The independent variables were measured using their corresponding items in the Balanced Measure of Psychological Needs (BMPN) instrument. The dependent variable was measured using the Utrecht Work Engagement Scale (UWES-9). An online survey resulted in 151 responses. Analysis of the collected data resulted in the removal of 17 responses, bringing the total sample for the study to 134 cases.

A standard multiple regression statistical model was created using IBM SPSS version 24. The results showed that three of the four predictors namely, CONFIDENCE, INTEREST, and AUTHENTICITY, were statistically significant in determining ENGAGEMENT ( $\mathrm{p}<.05)$. The fourth predictor, LONELINESS, was not significant in the determination of ENGAGEMENT ( $p>.05$ ). A final model was created using the three significant predictors and confirmed the previous findings. INTEREST was the best contributor to ENGAGEMENT, followed by AUTHENTICITY, then CONFIDENCE. This final model had an R-Square of .565 meaning that it explained 56.5 percent of the variance in ENGAGEMENT. In addition, the difference between the resulting R-Square and the Adjusted R-Square was not significant (1\%), suggesting that the model was generalizable to the population from which the sample derived. 


\subsection{Limitations}

While it is suggested that this study could be generalized to its population, it should be noted that this population is that employees in organizations within the U.S. Further study is required to generalize the findings to different countries.

In addition to the limited generalizability of the findings, this study used a self-reported online survey questionnaire. In such setting, there was no control over the answers provided by the participants and no follow-up could be made for clarification, thus the risk of bias. Nonetheless, the risk for bias data was reduced through the implementation of statistical functions that address bias. Indeed, the validation of the assumptions of multiple regression helped reduce some of the biased cases. All the same, there is no way to guarantee the removal of all bias in the final dataset.

\subsection{Implications and Future Studies}

From a practice standpoint, the implications of this study are first directed toward the workers. These findings can help current and future employees in the determination of their career plan. In seeking or determining their next career goals, current and future workers need first to identify their interests. This study confirmed that the person's interest was the best determinant of their engagement. By answering the question "Am I really doing what interests me?" or "Will I really be doing what interest me?", the person can have an idea of how engaged they will be in the selected job. Tying that job to their "true-self" and having confidence in their capability to complete tasks contribute to increasing the person's engagement in the job.

Just like with workers, managers can also use these findings to help employees stay engaged. For example, identifying employee's interests and assigning them tasks that align with those interests, which could mean shuffling tasks around, can help increase employee engagement in the organization. Managers also need to find ways of increasing employees' confidence in accomplishing their tasks. This can be done through the identification of training that can help them understand how to complete their tasks. In addition to the training, employees need to have the tools necessary for the task completion, which aligns with the definition of engagement as presented earlier which states that " $\ldots$ the organization provides the worker with the environment and conditions to be successful ..." (Lartey, 2021, p.137).

In addition to practice, the findings of this study have implications for scholars. First, it filled a gap in existing literature as no previous study analyzed the contribution of confidence, interest, authenticity, and loneliness to employee engagement. Furthermore, this study did not find a significant contribution of loneliness to employee engagement, as contrary to some previous studies.

In an article published in the Harvard Business Review, Moss (2018) posited that loneliness was the biggest struggle for remote workers, suggesting the establishment of a day when remote employees came into the office. Citing findings from a Gallup poll, Moss explained that remote workers who sporadically went to the office had a higher engagement rate. Similarly, Wang et al. (2021) identified loneliness as one of four key remote work challenges, in addition to work-home interference, ineffective communication, and procrastination. While these studies hint the existence of a relationship between loneliness and engagement, the current study did not find such relationship in the sample studied. One reason the relationship could not be established might reside in the composition of the sample. Indeed, Moss and Wang et al. focused on remote workers, while the sample used did not discriminate on the employees' work location. Further study could be instrumental in validating this finding.

\section{Conclusion}

The purpose of this study was to examine the relationship between the independent variables confidence, interest, authenticity, and loneliness as measured by the Balanced Measure of Psychological Needs (BMPN) and the dependent variable, employee engagement, as measured by the Utrecht Work Engagement Scale (UWES). An online survey using a self-reported questionnaire generated 151 responses. After validating the assumptions of multiple regression, 17 of the 151 responses were eliminated, bringing the final sample size to 134 cases. A standard multiple regression model was created using the final sample and the results indicated the existence of a statistically significant relationship between three of the independent variables (CONFIDENCE, INTEREST, and AUTHENTICITY) and the dependent variable (ENGAGEMENT). INTEREST was identified to be a better contributor to engagement as compared to the other variables, and AUTHENTICITY was better compared to CONFIDENCE. The findings from this study confirmed the premises of the self-efficacy theory and suggested that a model created with the three significant variables could explain 56.5 percent of variability in employee engagement. While previous studies indicated significant contribution of loneliness in engagement, this study did not corroborate those findings for the selected sample, thus offering an opportunity for further research. 


\section{Acknowledgments}

This study was fully funded by the authors without any external support or grant.

\section{References}

Bandura, A. (1994). Self-efficacy. In V. S. Ramachaudran (Ed.), Encyclopedia of human behavior (Vol. 4, pp. 71-81). New York: Academic Press.

Faul, F., Erdfelder, E., Lang, A. G., \& Buchner, A. (2007). G*Power 3: A flexible statistical power analysis program for the social, behavioral, and biomedical sciences. Behavior Research Methods, 39(2), 175-191. https://doi.org/10.3758/BF03193146

Field, A. (2013). Discovering statistics using IBM SPSS statistics (4th ed.). Thousand Oaks, California, United States of America: SAGE Publications.

Harter, J. K., Schmidt, F. L., \& Hayes, T. L. (2002). Business unit level outcomes between employee satisfaction, employee engagement and business outcomes: a meta-analysis. Journal of Applied Psychology, 87(2), 268-79. https://doi.org/10.1037/0021-9010.87.2.268

Johnston, M. M., \& Finney, S. J. (2010). Measuring basic needs satisfaction: Evaluating previous research and conducting new psychometric evaluations of the basic needs satisfaction in general scale. Contemporary Educational Psychology, 35(4), 280-296. https://doi.org/10.1016/j.cedpsych.2010.04.003

Kahn, W. A. (1990). Psychological conditions of personal engagement and disengagement at work. Academy of Management Journal, 33(4), 692-724. https://doi.org/10.5465/256287

Kahn, W. A. (1992). To be fully there: psychological presence at work. Human Relations, 45(4), 321-349. https://doi.org/10.1177/001872679204500402

Kim, W., Kolb, J. A., \& Kim, T. (2013). The relationship between work engagement and performance: a review of empirical literature and a proposed research agenda. Human Resource Development Review, 12(3), 248-276. https://doi.org/10.1177/1534484312461635

Kuntz, J., \& Roberts, R. (2014). Engagement and identification: an investigation of social and organizational predictors in an HR offshoring context. Strategic Outsourcing: An International Journal, 7(3), 253-274. https://doi.org/10.1108/SO-06-2014-0011

Lartey, F. M. (2021). Impact of career Planning, employee autonomy, and manager recognition on employee engagement. Journal of Human Resource and Sustainability Studies, 9(2), 135-157. https://doi.org/10.4236/jhrss.2021.92010

Lartey, F. M., \& Randall, P. M. (2021). Indicators of computer-mediated communication affecting remote employee engagement. Journal of Human Resource and Sustainability Studies, 9(2), 82-92. https://doi.org/10.4236/jhrss.2021.91006

Meyer, J. (1997). Organizational commitment. In Cooper, C.L. and Robertson, I.T. (Eds), International Review of Industrial and Organizational Psychology, 12, 175-228.

Moss, J. (2018). Helping remote workers avoid loneliness and burnout. Harvard Business Review. Retrieved from

https://covid-19.ukhc.org/wp-content/uploads/sites/121/2020/03/Helping-Remote-Workers-Avoid-Lonelines s-and-Burnout.pdf

Organ, D. W., \& Paine, J. B. (1999). A new kind of performance for industrial and organizational psychology: recent contribution to the study of organizational citizenship behavior. In Cooper, C. L., \& Robertson, I. T. (Eds), International Review of Industrial and Organizational Psychology, 14, 337-68.

Randall, P. M., Lartey, F. M., \& Tate, T. D., (2020). Enterprise Social Media (ESM) Use and Employee Belongingness in US Corporations. Journal of Human Resource Management, 8(3), 115-124. https://doi.org/10.11648/j.jhrm.201200803.12

Robertson, I. T., \& Cooper, C. L. (2010). Full engagement: the integration of employee engagement and psychological well-being. Leadership \& Organization Development Journal, 31(4), 324-336. https://doi.org/10.1108/01437731011043348

Ryan, R. M., \& Deci, E. L. (2000a). Intrinsic and extrinsic motivations: Classic definitions and new directions. Contemporary Educational Psychology, 25, 54-67. Retrieved March 3, 2008, from ScienceDirect Freedom Collection database. https://doi.org/10.1006/ceps.1999.1020 
Ryan, R. M., \& Deci, E. L. (2002). An overview of self-determination theory: An organismic-dialectical perspective. In E. L. Deci \& R. M. Ryan (Eds.), Handbook of self-determination research (pp. 3-33). Rochester, New York: The University of Rochester Press.

Ryan, R. M., \& Deci, E. L. (2017). Self-determination theory: Basic psychological needs in motivation, development, and wellness. New York: Guilford Publishing. https://doi.org/10.1521/978.14625/28806

Saks, A. M. (2006). Antecedents and consequences of employee engagement. Journal of Managerial Psychology 21(7), 600-619. https://doi.org/10.1108/02683940610690169

Schaufeli, W. B., \& Bakker, A. B. (2004). Job demands, job resources, and their relationship with burnout and engagement. Journal of Organizational Behavior, 25, 293-315. https://doi.org/10.1002/job.248

Schaufeli, W. B., Bakker, A. B., \& Salanova, M. (2006). The Measurement of Work Engagement with a Short Questionnaire: A Cross-National Study. Educational and Psychological Measurement, 66, 701-716. https://doi.org/10.1177/0013164405282471

Sheldon, K. M., \& Hilpert, J. C. (2012). The balanced measure of psychological needs (BMPN) scale: An alternative domain general measure of need satisfaction. Motivation and Emotion, 36, 439-451. https://doi.org/10.1007/s11031-012-9279-4

Shuck, B., \& Wollard, K. (2010). Employee engagement and HRD: A seminal review of the foundations. Human Resource Development Review, 9(1), 89-110. https://doi.org/10.1177/1534484309353560

Shuck, M. B., Rocco, T. S., \& Albornoz, C. A. (2011). Exploring employee engagement from the employee perspective: implications for HRD. Journal of European Industrial Training, 35(4), 300-325. https://doi.org/10.1108/03090591111128306

Tabachnick, B. G., \& Fidell, L. S. (2013). Using multivariate statistics (6th ed.). Upper Saddle River, NJ: Pearson.

Tate, D. T., Lartey, M. F., \& Randall, P. M. (2019). Relationship between computer-mediated communication and employee engagement among telecommuting knowledge workers. Journal of Human Resource and Sustainability Studies, 7(2). https://doi.org/10.4236/jhrss.2019.72021

Tate, D. T., Lartey, M. F., \& Randall, P. M. (2021). Do Performance Goals and Development, Feedback and Recognition, and A Climate of Trust Improve Employee Engagement in Small Businesses in the United States? International Business Research, 14(6). https://doi.org/10.5539/ibr.v14n6p1

Wang, B., Liu, Y., Qian, J., \& Parker, S. K. (2021). Achieving effective remote working during the COVID-19 pandemic: A work design perspective. Applied Psychology, 70(1), 16-59. https://doi.org/10.1111/apps.12290

\section{Copyrights}

Copyright for this article is retained by the author(s), with first publication rights granted to the journal.

This is an open-access article distributed under the terms and conditions of the Creative Commons Attribution license (http://creativecommons.org/licenses/by/4.0/). 